\title{
Binocular Summation of Contrast Remains Intact in Strabismic Amblyopia
}

\author{
Daniel H. Baker, ${ }^{1,2}$ Tim S. Meese, ${ }^{1}$ Bebzad Mansouri, ${ }^{2}$ and Robert F. Hess ${ }^{2}$
}

Purpose. Strabismic amblyopia is typically associated with several visual deficits, including loss of contrast sensitivity in the amblyopic eye and abnormal binocular vision. Binocular summation ratios (BSRs) are usually assessed by comparing contrast sensitivity for binocular stimuli ( sens $_{\text {BIN }}$ ) with that measured in the good eye alone (sens $\boldsymbol{G O O D}_{\mathrm{GOO}}$ ), giving BSR $=\boldsymbol{s e n s}_{\mathrm{BIN}} /$ sens $_{\mathrm{GOOD}}$. This calculation provides an operational index of clinical binocular function, but does not assess whether neuronal mechanisms for binocular summation of contrast remain intact. This study was conducted to investigate this question.

Methods. Horizontal sine-wave gratings were used as stimuli (3 or $9 \mathrm{cyc} / \mathrm{deg} ; 200 \mathrm{~ms}$ ), and the conventional method of assessment (above) was compared with one in which the contrast in the amblyopic eye was adjusted (normalized) to equate monocular sensitivities.

Results. In nine strabismic amblyopes (mean age, 32 years), the results confirmed that the BSR was close to unity when the conventional method was used (little or no binocular advantage), but increased to approximately $\sqrt{2}$ or higher when the normalization method was used. The results were similar to those for normal control subjects ( $n=3$; mean age, 38 years) and were consistent with the physiological summation of contrast between the eyes. When the normal observers performed the experiments with a neutral-density (ND) filter in front of one eye, their performance was similar to that of the amblyopes in both methods of assessment.

Conclusions. The results indicate that strabismic amblyopes have mechanisms for binocular summation of contrast and that the amblyopic deficits of binocularity can be simulated with an ND filter. The implications of these results for best clinical practice are discussed. (Invest Ophthalmol Vis Sci. 2007;48: 5332-5338) DOI:10.1167/iovs.07-0194

mblyopia is a developmental condition that arises when
the input to one eye is disturbed during a critical period.
Common causes of disturbance include strabismus (squint),
anisometropia (refractive difference between the eyes), and
congenital cataract. Amblyopes usually have abnormal binocu-
lar vision and contrast sensitivity that is impaired in the af-
fected eye, often severely. ${ }^{1-4}$ If the ocular defect is not cor-

From the ${ }^{1}$ Department of Optometry, School of Life and Health Sciences, Aston University, Birmingham, United Kingdom; and ${ }^{2}$ McGill Vision Research, Department of Ophthalmology, McGill University, Montreal, Quebec, Canada.

Supported by U.K. Engineering and Physical Sciences Research Council Grant GR/S74515/01 (TSM) and Canadian Institutes of Health Research Grants MOP53346; MT108-18 (RFH).

Submitted for publication February 14, 2007; revised June 19, 2007; accepted September 4, 2007.

Disclosure: D.H. Baker, None; T.S. Meese, None; B. Mansouri, None; R.F. Hess, None

The publication costs of this article were defrayed in part by page charge payment. This article must therefore be marked "advertisement" in accordance with 18 U.S.C. $\$ 1734$ solely to indicate this fact

Corresponding author: Daniel H. Baker, Department of Optometry, School of Life and Health Sciences, Aston University, Birmingham, UK; d.h.baker@soton.ac.uk. rected until after the critical period, the deficits remain into adulthood. ${ }^{5}$ Because these visual deficits cannot be corrected optically or surgically, the problem is likely to be neurological and presumably cortical, ${ }^{6,7}$ though some work has also implicated the lateral geniculate nucleus.8,9

Of particular interest is abnormal binocular contrast vision, which has been revealed by acuity tasks, ${ }^{10-12}$ and poor binocular summation of contrast at detection threshold..$^{3,4,13-17}$ The binocular summation ratio is the ratio of binocular to monocular sensitivities, often measured for sine-wave gratings, and is an indication of binocular advantage. For example, a binocular summation ratio of unity indicates no binocular advantage, whereas a ratio of two indicates that contrast sensitivity is twice as high with two eyes as with one.

The binocular summation ratio for normal observers is $\sim 1.4$ $(\sqrt{ } 2),{ }^{18}$ or, typically, slightly higher, ${ }^{19-21}$ and is attributed to physiological summation of the two monocular signals. ${ }^{18,21-23}$ However, binocular summation ratios are typically lower than this in amblyopic observers (near unity), particularly at high spatial frequencies. ${ }^{14}$ This has led to a view that mechanisms for binocular summation of contrast are compromised in amblyopia and are possibly absent at higher spatial frequencies. ${ }^{3,4,10}$ This in turn is supported by findings in studies at the cellular level in which kittens with artificially induced strabismus have been found to have fewer binocular neurons than normal. ${ }^{6,24,25}$

However, another interpretation is possible. In most clinical studies, the binocular summation ratio is expressed as binocular sensitivity relative to the monocular performance of the

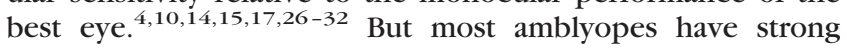
asymmetries of contrast sensitivity across the eyes. Thus, the contribution from the amblyopic eye during binocular stimulation may be too weak to affect performance. ${ }^{10}$ In other words, conventional measures of binocular summation ratios provide a useful operational metric for binocular advantage, but do not indicate the integrity of neural convergence of signals between the eyes. To address this problem, we used horizontal sine-wave gratings (3 or $9 \mathrm{cyc} / \mathrm{deg}$ ) to measure contrast sensitivity for each of the two eyes in both amblyopic and normal observers. We then adjusted the contrast in the less sensitive eye, to equate monocular detectability for binocular gratings. From this, we derived unbiased estimates of binocular summation.

\section{Methods}

\section{Apparatus and Stimuli}

Stimuli were presented on a monitor $(120 \mathrm{~Hz}$, mean luminance 200 $\mathrm{cd} / \mathrm{m}^{2}$; Clinton Monoray; Cambridge Research Systems [CRS], Kent, UK) using a specialist stimulus generator (VSG 2/5; CRS) controlled by a computer and gamma-corrected to ensure linearity. Ferroelectric shutter goggles (CRS, FE-1) were used to present grating contrasts to the two eyes independently by synchronizing the goggles with the monitor and using a frame-interleaving technique. This setup gave an image refresh rate of $60 \mathrm{~Hz}$. The goggles acted as a neutral-density (ND) filter (an attenuation of $0.6 \log$ units) and further halved the overall luminance because they were closed on every other frame for each eye. Thus, the effective mean luminance was $25 \mathrm{~cd} / \mathrm{m}^{2}$. 
TABLE 1. Clinical and Demographic Details of Amblyopic Observers

\begin{tabular}{|c|c|c|c|c|c|c|c|c|}
\hline Obs. & Eye & Type & Refraction & Acuity & $\begin{array}{c}\text { Grating } \\
\text { Acuity }\end{array}$ & Squint & Prism & History, Stereo \\
\hline $\begin{array}{l}\text { ADS } \\
21 / F\end{array}$ & $\begin{array}{l}\text { RE } \\
\mathrm{LE}\end{array}$ & $\begin{array}{l}\text { Strab. } \\
\text { Normal }\end{array}$ & $\begin{array}{c}\varnothing \\
-0.5 \mathrm{DS}\end{array}$ & $\begin{array}{l}20 / 125 \\
20 / 20\end{array}$ & $\begin{array}{l}35.9 \\
45.0\end{array}$ & ET $15^{\circ}$ & $10 \mathrm{D}$ & $\begin{array}{l}\text { Detected age } 4 \mathrm{y} \text {, patching at } \\
4 \mathrm{y} \text { for } 6 \mathrm{mo} \text {, surgery at } 7 \mathrm{y}\end{array}$ \\
\hline $\begin{array}{l}\text { AR } \\
47 / M\end{array}$ & $\begin{array}{l}\text { RE } \\
\text { LE }\end{array}$ & $\begin{array}{l}\text { Normal } \\
\text { Strab. }\end{array}$ & $\varnothing$ & $\begin{array}{l}20 / 20 \\
20 / 50\end{array}$ & $\begin{array}{l}39.9 \\
24.5\end{array}$ & ET $1^{\circ}$ & None & $\begin{array}{r}\text { Detected age } 20 \mathrm{y} \text {, no } \\
\text { patching, no glasses }\end{array}$ \\
\hline $\begin{array}{l}\text { EMD } \\
43 / F\end{array}$ & $\begin{array}{l}\mathrm{RE} \\
\mathrm{LE}\end{array}$ & $\begin{array}{l}\text { Normal } \\
\text { Strab. }\end{array}$ & $\begin{array}{l}+0.75 \text { DS } \\
+0.75 \text { DS }\end{array}$ & $\begin{array}{l}20 / 16 \\
20 / 63\end{array}$ & $\begin{array}{l}60.9 \\
26.4\end{array}$ & ET $5^{\circ}$ & $3 \mathrm{D}$ & $\begin{array}{l}\text { Detected age } 6 \mathrm{y} \text {, patching } \\
\text { for } 1 \mathrm{y} \text {, near normal local } \\
\text { stereo }\end{array}$ \\
\hline $\begin{array}{l}\text { GN } \\
31 / M\end{array}$ & $\begin{array}{l}\mathrm{RE} \\
\mathrm{LE}\end{array}$ & $\begin{array}{l}\text { Strab. } \\
\text { Normal }\end{array}$ & $\begin{array}{l}+5-2,120^{\circ} \\
+3.5-1,75^{\circ}\end{array}$ & $\begin{array}{l}20 / 200 \\
20 / 20\end{array}$ & $\begin{array}{l}26.4 \\
61.0\end{array}$ & ET $8^{\circ}$ & $3 \mathrm{D}$ & $\begin{array}{l}\text { Detected age } 5 \mathrm{y} \text {, patching } 3 \\
\text { mo, surgery at } 10 \mathrm{y}\end{array}$ \\
\hline $\begin{array}{l}\text { JL } \\
29 / M\end{array}$ & $\begin{array}{l}\mathrm{RE} \\
\mathrm{LE}\end{array}$ & $\begin{array}{l}\text { Normal } \\
\text { Mixed }\end{array}$ & $\begin{array}{c}\varnothing \\
+2.5 \text { DS }\end{array}$ & $\begin{array}{l}20 / 20 \\
20 / 40\end{array}$ & $\begin{array}{l}44.9 \\
35.7\end{array}$ & $\mathrm{XT} 20^{\circ}$ & $10 \mathrm{D} \times 2$ & $\begin{array}{l}\text { Detected age } 4 \mathrm{y} \text {, no } \\
\text { patching }\end{array}$ \\
\hline $\begin{array}{l}\mathrm{KDJ} \\
22 / \mathrm{M}\end{array}$ & $\begin{array}{l}\mathrm{RE} \\
\mathrm{LE}\end{array}$ & $\begin{array}{l}\text { Strab. } \\
\text { Normal }\end{array}$ & $+1 \mathrm{DS}$ & $\begin{array}{l}20 / 50 \\
20 / 25\end{array}$ & $\begin{array}{l}29.9 \\
49.0\end{array}$ & $\mathrm{XT} 4.5^{\circ}$ & $3 \mathrm{D}$ & $\begin{array}{l}\text { Detected age } 5 \mathrm{y} \text {, patching } \\
\text { for } 6 \text { mo and glasses until } \\
14 \mathrm{y}\end{array}$ \\
\hline $\begin{array}{l}\text { ML } \\
24 / F\end{array}$ & $\begin{array}{l}\mathrm{RE} \\
\mathrm{LE}\end{array}$ & $\begin{array}{l}\text { Mixed } \\
\text { Normal }\end{array}$ & $\begin{array}{c}+1.0-0.7590^{\circ} \\
-3.25 \mathrm{DS}\end{array}$ & $\begin{array}{l}20 / 80 \\
20 / 25\end{array}$ & $\begin{array}{l}31.2 \\
37.2\end{array}$ & ET $6^{\circ}$ & $3 \mathrm{D}$ & $\begin{array}{l}\text { Detected age } 5 \mathrm{y} \text {, patching } \\
\text { for } 2 \mathrm{y}\end{array}$ \\
\hline $\begin{array}{l}\mathrm{RDB} \\
51 / \mathrm{F}\end{array}$ & $\begin{array}{l}\mathrm{RE} \\
\mathrm{LE}\end{array}$ & $\begin{array}{l}\text { Normal } \\
\text { Strab. }\end{array}$ & $\begin{array}{l}+3.25 \mathrm{DS} \\
+4.75-0.75,45^{\circ}\end{array}$ & $\begin{array}{l}20 / 15 \\
20 / 40\end{array}$ & $\begin{array}{l}46.5 \\
32.3\end{array}$ & $\mathrm{XT} 15^{\circ}$ & $8 \mathrm{D}$ & $\begin{array}{l}\text { Detected age } 6 \mathrm{y} \text {, no } \\
\text { patching, no surgery }\end{array}$ \\
\hline $\begin{array}{l}\mathrm{VD} \\
24 / \mathrm{F}\end{array}$ & $\begin{array}{l}\mathrm{RE} \\
\mathrm{LE}\end{array}$ & $\begin{array}{l}\text { Normal } \\
\text { Strab. }\end{array}$ & $\begin{array}{l}+0.25 \mathrm{DS} \\
+2.75 \mathrm{DS}\end{array}$ & $\begin{array}{l}20 / 20 \\
20 / 40\end{array}$ & - & ET $3^{\circ}$ & $3 \mathrm{D}$ & $\begin{array}{l}\text { Detected age } 5 \mathrm{y} \text {, patching, } \\
\text { no surgery }\end{array}$ \\
\hline
\end{tabular}

Grating acuity is in cycles per degree, for horizontal gratings. Visual acuity was assessed with a logMAR chart. Unless otherwise stated, subjects had not undergone surgery to correct strabismus. Apart from EMD, all amblyopes were stereoblind, as measured with a random dot chart. Eccentric fixation was measured with a visuscope, and subjects with gross eccentric fixation were excluded from the study. Obs., observer; M, male; F, female; Strab., strabismus; RE, right eye; LE, left eye; ET, esotropia; XT, exotropia; $\varnothing$, no correction required.

Stimuli were large $\left(\right.$ diameter, $5^{\circ}$ ) circular patches of horizontal sinusoidal grating, with a spatial frequency of either $3 \mathrm{cyc} / \mathrm{deg}(15$ cycles full width) or $9 \mathrm{cyc} / \mathrm{deg}$ ( 45 cycles full width). A raised sine envelope with a period of $1^{\circ}$ smoothed the outer edge of the stimulus. The grating stimuli were presented to either the left or right eye only (monocular) or both eyes simultaneously (binocular). Note that in all three conditions, the same mean luminance was presented to both eyes (i.e., patching was not used in the monocular conditions). The contrast of the target grating was controlled using look-up tables and pseudo 15-bit resolution, and is expressed as Michelson contrast in percent:

$$
c=100\left(\frac{L_{\max }-L_{\min }}{L_{\max }+L_{\min }}\right) .
$$

The phase of the grating relative to a central fixation point was chosen randomly on each trial from one of four values $\left(0^{\circ}, 90^{\circ}, 180^{\circ}\right.$, and $\left.270^{\circ}\right)$. Stimuli were presented for $200 \mathrm{~ms}$ in one of two intervals, each marked by a beep, and separated by an interstimulus interval of $500 \mathrm{~ms}$.

\section{Observers}

Three normal observers (authors DHB, RFH, and BM) participated as the control. All were men with good stereovision (DHB, 24 years, emmetropic, 20/20; RFH, 56 years, L -3.00 DS, R -3.25 DS, 20/16; BM, 35 years, emmetropic, 20/20). These observers completed the conventional summation experiment (described later) under normal viewing conditions and also with a $1.5-\log$ unit neutral-density (ND) filter over the weaker eye (defined as the eye yielding the highest monocular threshold during normal viewing). The purpose of the filter was to reduce the sensitivity of one eye, with the goal of reducing the binocular summation ratio measured in the conventional way. ${ }^{33}$ The normalization experiment was also completed with the ND filter. We refer to the eye with the ND filter as the bad eye in normal observers, for convenient comparison with the amblyopes.
Nine adult strabismic amblyopes completed the study, and were reimbursed for their time. Their clinical and demographic details are given in Table 1. All subjects wore their normal optical corrections (having been verified with a subjective refraction) during testing. Observers gave informed consent to participate in the study in accordance with the Declaration of Helsinki and the ethical guidelines of the host institution (McGill University).

\section{Procedure and Analysis}

Before testing began, the size of strabismus was measured for each amblyopic observer with an amblyoscope (Lyle Major Amblyoscope; Clement Clarke Ltd., Harlow, UK). This device required the observers to move a handle until a nonius figure (a central circle with vertical lines above for one eye and below for the other) was correctly aligned. The adjustment from zero that was indicated by the instrument is shown in Table 1 . We then used prisms to compensate for the strabismus, so that the figure was aligned when the instrument read zero. The appropriate prism was attached to the front of the goggles so that the eyes were correctly aligned and converged on a central fixation point during testing.

Observers were seated in a darkened room, $114 \mathrm{~cm}$ from the display. The goggles were held on the head by an elasticized strap. Performance was measured with a two-interval, forced-choice (2IFC) method in which observers indicated which of two intervals contained the test grating by pressing one of two mouse buttons. Intervals were marked with an auditory beep, and auditory feedback was given to indicate correctness of response. In the initial experiment (analyzed in the conventional way), monocular ( $\operatorname{sens}_{\mathrm{L}}$ and $\operatorname{sens}_{\mathrm{R}}$ ) and binocular $\left(\right.$ sens $\left._{\text {BIN }}\right)$ sensitivities (the reciprocal of detection thresholds) were estimated in an interleaved design (described later). Thus, observers were not precued to the stimulus conditions. In this experiment, the binocular summation ratio $(B S R)$ was given by $B S R=\operatorname{sens}_{\mathrm{BIN}} /$ sens $_{\mathrm{BEST}}$, where sens $_{\mathrm{BEST}}$ was the greater sensitivity measured in the two monocular conditions. 

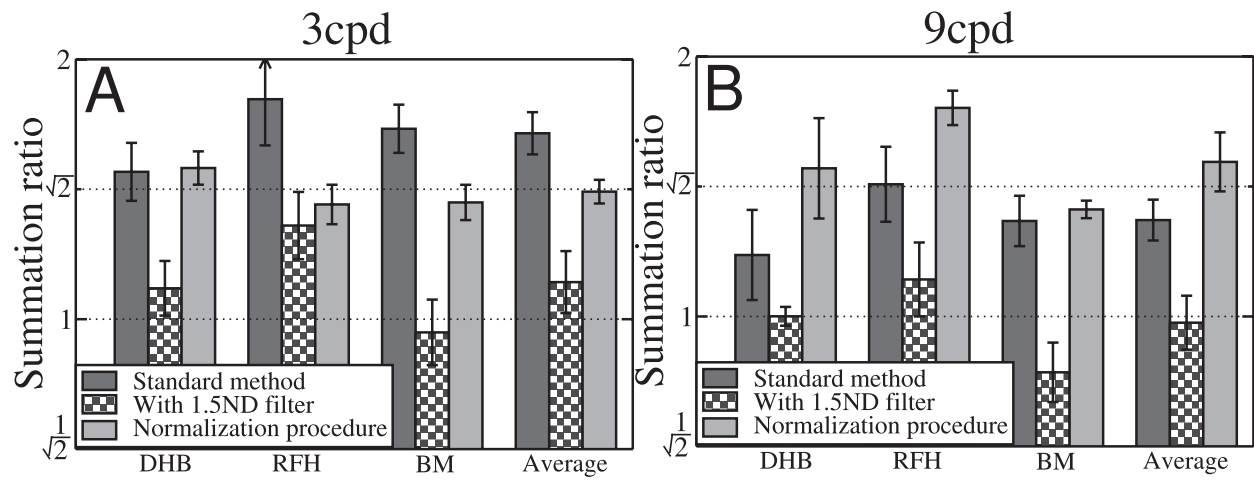

FIGURE 1. Binocular summation ratios for normal observers. Data are shown for (A) 3-and (B) 9-cyc/deg gratings. Ratios were determined using the conventional method, in which binocular sensitivity is compared with monocular sensitivity of the most sensitive eye, both with and without an ND filter. Results are also shown for the normalization procedure. Error bars are $\pm 1 \mathrm{SE}$ of the geometric means of the summation ratios over six repetitions for individual observers and across three observers for the average.

For the normalization experiment, there were two stages. The two monocular conditions were run first to give estimates of the sensitivity to the good $\left(\operatorname{sen}_{\mathrm{GOOD}}\right)$ and amblyopic $\left(\right.$ sens $\left._{\mathrm{AMB}}\right)$ eyes, using an interleaved design. (Equivalently, for the normal observers this method was used for the eye with the ND filter.) To normalize the contrasts in the binocular stimulus, the contrast presented to the amblyopic eye was adjusted by the factor sens $\boldsymbol{G}_{\mathrm{GOOD}} /$ sens $_{\mathrm{AMB}}$. A binocular condition was then run to determine $\operatorname{sens}_{\mathrm{BIN}}$ and the ratio $B S R=\operatorname{sens}_{\mathrm{BIN}} / \operatorname{sens}_{\mathrm{GOOD}}$.

Each experimental session lasted up to 10 minutes and involved several three-down, one-up staircases, ${ }^{34}$ which adjusted stimulus contrast in logarithmic steps around threshold (3-dB step size, 12 reversals, $\sim 40$ trials per staircase). In the conventional experiment, one staircase was used for each eye, and a third staircase was used for the binocular condition. In the normalization experiment, pairs of staircases ${ }^{35}$ were used for each of the three conditions.

Thresholds and slopes of the psychometric functions were determined for each session by Probit analysis. ${ }^{36}$ This procedure fits a cumulative log-Gaussian function to the staircase data with a guess rate of $50 \%$ (appropriate for 2IFC). Threshold was taken to be the $75 \%$ correct point on the fitted function, and slope was given by its $\mathrm{SD}(\sigma)$ in $\log$ units, which was then converted to the more familiar $\beta$ parameter from the Weibull function by the conversion $\beta=0.515 / \sigma \sigma^{37}$ Observers completed four (amblyopes) or six (controls) repetitions of the conventional experiment and six repetitions of the normalization experiment.

\section{Results}

Binocular summation ratios for the normal observers (controls) are shown in Figure 1. Using the conventional method of analysis, all observers showed normal binocular summation ratios $>\sqrt{ } 2$ for 3 -cyc/deg gratings, consistent with neural binocular summation. ${ }^{18,21}$ For all three observers, the level of binocular summation was slightly less with 9-cyc/deg gratings, perhaps because of small asymmetries in detection thresholds between the eyes (Table 2), or slight stimulus misalignments (see the Discussion section). As expected, when an ND filter

Table 2. Interocular Sensitivity Ratios and Psychometric Slopes $(\beta)$ for the Two Stimuli

\begin{tabular}{|c|c|c|c|c|c|c|c|c|}
\hline \multirow[b]{2}{*}{ Subject } & \multicolumn{4}{|c|}{3 cyc/deg } & \multicolumn{4}{|c|}{$9 \mathrm{cyc} / \mathrm{deg}$} \\
\hline & $\begin{array}{c}\text { Interocular } \\
\text { Sensitivity } \\
\text { Ratio }\end{array}$ & $\begin{array}{c}\text { Good } \\
\text { Eye } \\
\beta\end{array}$ & $\begin{array}{c}\text { Bad } \\
\text { Eye } \\
\beta\end{array}$ & $\begin{array}{c}\text { Binocular } \\
\beta\end{array}$ & $\begin{array}{c}\text { Interocular } \\
\text { Sensitivity } \\
\text { Ratio }\end{array}$ & $\begin{array}{c}\text { Good } \\
\text { Eye } \\
\beta\end{array}$ & $\begin{array}{c}\text { Bad } \\
\text { Eye } \\
\beta\end{array}$ & $\begin{array}{c}\text { Binocular } \\
\beta\end{array}$ \\
\hline \multicolumn{9}{|l|}{ Normal } \\
\hline DHB & $5.04(1.20)$ & 4.26 & 4.06 & 4.65 & $6.12(1.06)$ & 2.88 & 2.60 & 2.16 \\
\hline RFH & $7.45(1.70)$ & 5.46 & 5.07 & 5.18 & $9.00(1.70)$ & 3.28 & 5.33 & 6.97 \\
\hline BM & $5.87(1.13)$ & 3.43 & 4.09 & 4.42 & $9.97(1.26)$ & 2.66 & 4.65 & 3.51 \\
\hline Mean & $6.04(1.32)$ & 4.31 & 4.38 & 4.74 & $8.06(1.32)$ & 2.93 & 4.01 & 3.75 \\
\hline \multicolumn{9}{|l|}{ Strabismic } \\
\hline ADS & 2.23 & 2.65 & 2.01 & 2.05 & 3.51 & 1.36 & 1.97 & 2.29 \\
\hline AR & 11.24 & 2.14 & 2.14 & 3.60 & 13.20 & 0.64 & 1.41 & 1.39 \\
\hline EMD & 1.59 & 4.28 & 3.66 & 4.85 & 1.78 & 3.38 & 4.59 & 3.93 \\
\hline GN & 3.57 & 2.58 & 1.94 & 2.49 & - & - & - & - \\
\hline $\mathrm{JL}$ & 2.91 & 4.19 & 3.74 & 3.32 & 10.20 & 3.81 & 1.93 & 4.94 \\
\hline KDJ & 8.20 & 2.06 & 1.66 & 2.66 & - & - & - & - \\
\hline ML & 1.45 & 4.82 & 3.91 & 3.33 & 2.86 & 2.07 & 3.20 & 3.41 \\
\hline RDB & 1.18 & 3.92 & 2.18 & 2.78 & - & - & - & - \\
\hline VD & 1.19 & 4.27 & 3.04 & 5.14 & 1.38 & 3.73 & 3.22 & 5.87 \\
\hline Mean & 2.67 & 3.28 & 2.57 & 3.22 & 3.87 & 2.10 & 2.52 & 3.27 \\
\hline
\end{tabular}

All data are from the normalization experiment, except those in parentheses and are geometric means averaged across six replications of the experiment. Slope values are equivalent Weibull $\beta$, which is constrained to values $\leq 8$. The interocular ratio is defined as sens $s_{\mathrm{GOOD}} /$ sens $_{\mathrm{AMB}}$, with values $>1$ indicating that the good eye was more sensitive than the amblyopic (or filtered) eye. For the normal observers, italicized values indicate ratios without an ND filter. 

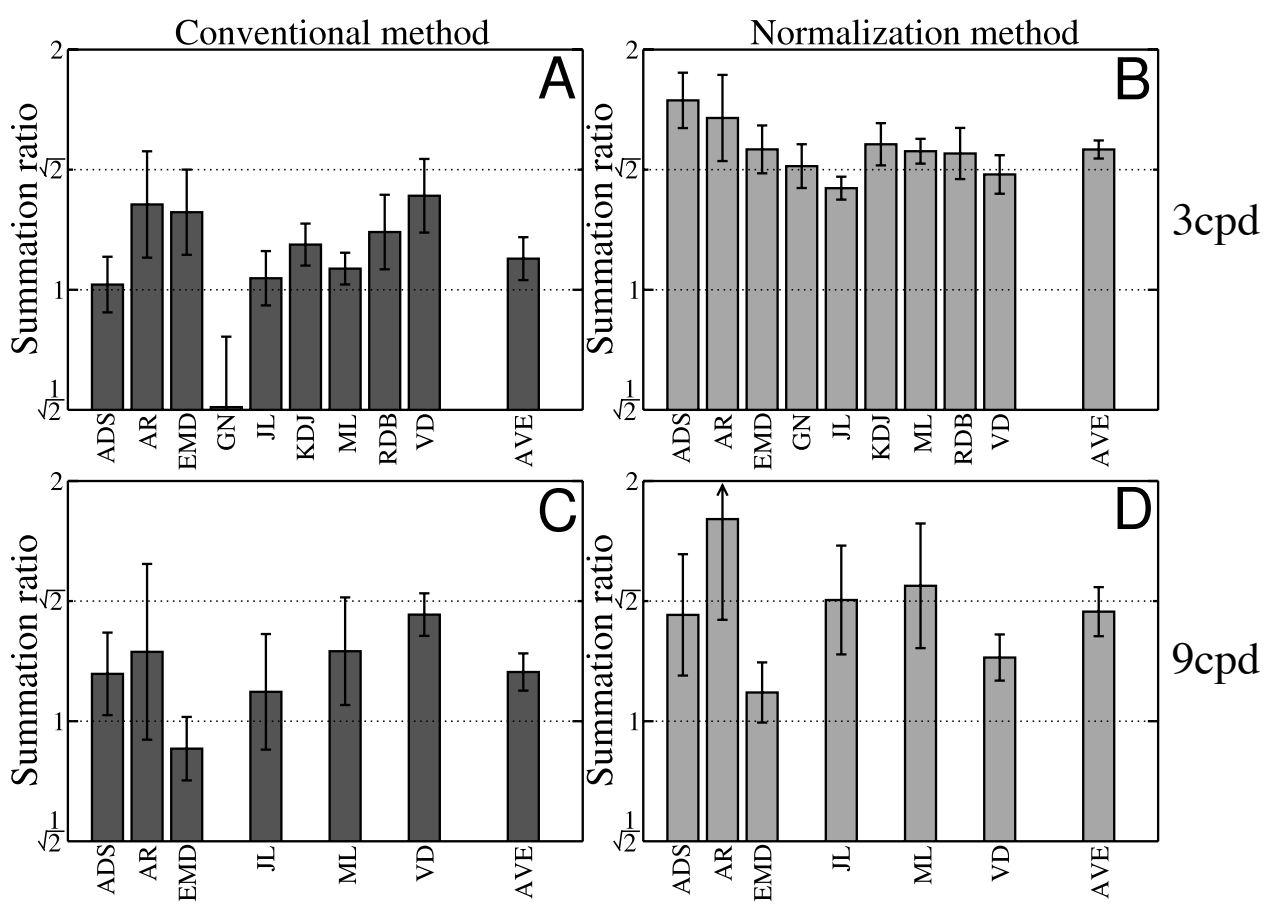

FIGURE 2. Binocular summation ratios for amblyopic observers, using either the $(\mathbf{A}, \mathbf{C})$ conventional or (B, D) normalization method, at (A, B) 3 or (C, D) 9 cyc/deg. Error bars are \pm 1 SE of the geometric means of the binocular summation ratio across four or six repetitions for individual observers, or across observers for the average (AVE).

was placed in front of one eye and the experiment repeated, the binocular summation ratios were greatly reduced (Fig. 1). This was probably because of the change in sensitivity caused by the filter ${ }^{38}$; monocular thresholds for the filtered eye increased by a factor of five or more. This finding was confirmed by the normalization method (Fig. 1), in which the binocular summation ratio returned to normal levels. This result suggests that with the ND filter, the process of binocular summation remains intact, but is obscured in the conventional analysis, which does not compensate for the low sensitivity.

Results for the amblyopic observers are shown in Figure 2 for both spatial frequencies. Binocular summation ratios were consistently $<\sqrt{2}$ for all the amblyopes when the conventional analysis was used (Figs. 2A, 2C) and were often close to unity, as has been found before. ${ }^{4,14}$ As expected, sensitivity was poorer in the amblyopic eye, by as much as a factor of 13 (Table 2). When the normalization procedure was used (Figs. 2B, 2D), the binocular summation ratios were within the normal range, exceeding $\sqrt{ } 2$ in most cases. With the 3-cyc/deg gratings, the group average (geometric mean) binocular summation ratio increased from 1.09 to 1.50 across the two methods.

With the 9-cyc/deg gratings, the same pattern of results were obtained in four of six amblyopic observers and the group average increased from 1.15 to 1.37 across the two methods. The weaker overall effect at $9 \mathrm{cyc} / \mathrm{deg}$ was largely because the normalization procedure was not effective for subjects EMD and VD. We consider the results for these two observers further in the Discussion section.

In addition to measuring thresholds and binocular summation ratios, we also measured the slopes of the psychometric functions (Table 2). These tended to be slightly shallower in the amblyopic observers than the normal subjects, though in most cases they were within normal bounds for this type of experiment $(\beta>2) .{ }^{19,21,39}$ We discuss the importance of these results in the next section.

\section{Discussion}

Using a binocular summation paradigm, we found that strabismic amblyopes show normal levels of binocular contrast summation for horizontal sine-wave gratings when binocular stimulus strength is normalized to the detection thresholds for each eye. We also demonstrated that the same approach can ameliorate the loss of binocular summation in normal observers when an ND filter attenuates the luminance to one eye.

\section{Probability Summation and Physiological Summation}

The present experiments were designed to assess the physiological convergence of contrast signals from the two eyes. However, a theoretical alternative that should also be considered is that of probability summation. A thorough contemporary analysis for 2IFC was presented by Tyler and Chen, ${ }^{40}$ involving a MAX operation across channels (or eyes). For several situations, their analysis showed that probability summation for two equally detectable signals is approximately a factor of 1.2 (a fourth-root rule), considerably less than the quadratic $(\sqrt{2})$ and greater summation found in our study and elsewhere. ${ }^{18-21}$ However, they also showed that a MAX rule can produce higher levels of summation $(\sim \sqrt{2})$ under certain plausible but specific conditions. These are: (1) that the contrast transducer is linear, (2) that noise is late and additive, and (3) that the stimulus that excites the greatest number of mechanisms (in this case, the binocular grating) fills the attentional window (the set of noisy mechanisms monitored by the observer). However, this model arrangement also predicts that the psychometric function would be very shallow: a Weibull $\beta \sim 1.3$ (i.e., a $d^{\prime}$ slope of unity). Typically, we found much steeper psychometric functions than this with both normal and amblyopic observers (see Table 2). The model psychometric function can be made steeper by either increasing stimulus uncertainty (the size of the attentional window) or introducing an 
accelerating contrast transducer, but both of these manipulations result in a loss of summation by the MAX rule. Thus, probability summation cannot account for the binocular summation measured in the present study. An interpretation in terms of linear physiological summation is consistent with steep psychometric slopes and high levels of binocular summation and therefore is more likely. ${ }^{21}$

\section{Binocularity in Strabismic Amblyopes}

The results are strong evidence that binocular summation of luminance contrast is not as severely compromised in amblyopia as is often thought. This suggests that in human amblyopes, binocular cells can be driven by amblyopic and fellow eyes, contrary to findings from single-cell studies on artificially strabismic cats, which indicate a substantial reduction in binocularity. ${ }^{6,24,25}$ The apparent absence of binocular summation in previous human studies is most likely attributable to the sensitivity difference between the eyes, as we have demonstrated in normal observers with ND filters. Presumably the filter does not interfere with neural convergence, but reduces contrast sensitivity to such an extent that the contrast energy in the filtered eye is too low to improve binocular sensitivity over that achieved by the unfiltered eye. We suggest that a similar process occurs in strabismic amblyopia when monocular thresholds are substantially different in the good and amblyopic eyes.

This hypothesis is consistent with the finding that the degree of binocular summation in a group of optically reared anisometropic behaving monkeys correlated with the interocular contrast sensitivity difference. ${ }^{41}$ In human amblyopes, Pardhan and Gilchrist ${ }^{14}$ found that the reduction in binocular summation was determined by the threshold difference between the two eyes. They also found evidence of interocular suppression at threshold (summation ratios, $<1$ ), which we rarely observed in the present study, most likely because such processes are restricted to particular subpopulations. ${ }^{17}$

As with any clinical study, there are likely to be exceptions to the general trends. For example, the four stereoblind observers of Lema and Blake ${ }^{13}$ were deliberately chosen to have equal contrast sensitivity functions for their two eyes and showed no binocular summation at any spatial frequency tested $(2-6.5 \mathrm{cyc} / \mathrm{deg})$. The normalization procedure would not be expected to change this, because the sensitivities of the two eyes were the same (i.e., no normalization was needed). Thus, it is clear that binocular summation cannot be intact in all stereoblind observers, but that it is preserved in the observers with unilateral strabismus in our study. Furthermore, we are not making the strong claim that binocular summation remains intact in all amblyopes. We have not investigated anisometropic, deprivation, or meridional amblyopes, and so the issue remains open for these groups. It also remains possible that binocular summation is lost in other strabismic amblyopes not tested in our study. ${ }^{17}$

\section{Stereopsis in Adult Amblyopes}

If the binocular summation process is intact in the observers here, why do none of them have normal stereopsis (Table 1)? One possibility is that when stereovision is assessed, the stimuli presented to the amblyopic eye are not sufficiently above threshold to activate stereopsis mechanisms. ${ }^{42,43}$ This explanation seems unlikely to be the complete one ${ }^{44}$ for two reasons. First, stereopsis is tolerant to differences in contrast at high spatial frequencies. ${ }^{45-47}$ Second, when the images are equated for contrast at high spatial frequencies, stereopsis is not normal, even in anisometropes. ${ }^{16}$

Another possibility is that stereo mechanisms may be dysfunctional, even though binocular summation of contrast survives. The cortical sites of these two processes are very different; bin- ocular summation of neural signals occurs early in area V1; however, relative disparity processing occurs in extrastriate area $\mathrm{V} 2 .{ }^{48}$

A further possibility is that the amblyopic binocular system may be intact for horizontal structures (such as the gratings here), but deficient for vertical structures, ${ }^{49,50}$ which are much more important for stereopsis. ${ }^{51}$ We used horizontal gratings in this study because they are much less prone to image registration errors due to poor ocular convergence, which becomes increasingly problematic in normal observers as well as amblyopes as spatial frequency increases. Further experiments are needed to assess performance with vertical stimuli, though it might be difficult to overcome the problems of misregistration. Such misregistration may also explain the failure of our procedure with observers EMD and VD at $9 \mathrm{cyc} / \mathrm{deg}$. At this spatial frequency a vertical misalignment of only $3.33 \mathrm{arcmin}$ is needed for the gratings to be in antiphase in the two eyes-a situation that is known to abolish binocular summation ${ }^{52,53}$ and to be well within the range of normal vertical vergence error. $^{51,54}$ One alternative account is very unlikely. Since EMD and VD had the lowest interocular sensitivity ratios at $9 \mathrm{cyc} / \mathrm{deg}$ (Table 2), binocular imbalance cannot be the critical factor.

\section{Cortical Development and Clinical Practice}

It seems likely that balanced binocular input is a prerequisite for the development of stereovision, ${ }^{45,46,55-57}$ which explains why it fails to develop in strabismic children, even after patching. With normal viewing, the amblyopic eye will provide only a weak signal, which is presumably suppressed by strong signals in the other eye. ${ }^{14,19,21,58-61}$ When a patch is worn over the good eye, the suppression from the good eye is reduced, and the amblyopic eye will stimulate binocular cells. Under these circumstances, however, there is no excitation from the good eye. Thus, patching prevents the eyes from ever working in tandem, and a balanced input is never available.

The present study suggests an alternative treatment. To balance the eyes, the good eye must be disadvantaged, so that it is equivalent to the bad eye. The similarity between the strabismic amblyopes and normal control subjects with an ND filter suggests that an ND filter placed over the good eye might be more appropriate than total occlusion (patching). The use of the filter is further supported by two studies on binocular rivalry, which reached similar conclusions using ND filters. ${ }^{62,63}$ We know of no clinical trials involving this method, but a similar approach has been made using a diffuser to blur the image in the good eye. For example, Bangerter foils are used occasionally in treating amblyopia. ${ }^{64}$ They can be attached to standard spectacle lenses and produce much less psychological and cosmetic impact than a patch. Whether the drop in luminance produced by an ND filter is critical to our results remains unclear, but such filters can easily be calibrated to the particular sensitivity loss in individual amblyopic patients. Such a treatment should provide equal inputs to binocular cells and may allow the development of stereo mechanisms in children with amblyopia (provided that the strabismus has been corrected surgically).

\section{Conclusions}

It is well known that strabismic amblyopes have abnormally low binocular summation ratios, and this knowledge has led to a view that their binocular mechanisms may be deficient. ${ }^{10,17,32,65,66}$ However, we have shown that when contrast sensitivity is normalized across the eyes, binocular summation is normal, indicating that binocular contrast mechanisms remain intact. This finding has important ramifications for best practice in the treatment of amblyopia, which we hope to see assessed in future clinical trials. 


\section{Acknowledgments}

The authors thank Oliver Ehrt, who kindly performed the eye examinations in some of our amblyopic observers, and Ben Thompson for providing grating acuity data.

\section{References}

1. Hess RF. Contrast sensitivity assessment of functional amblyopia in humans. Trans Ophthalmol Soc UK. 1979;99:391-397.

2. Hess RF, Howell ER. The threshold contrast sensitivity function in strabismic amblyopia: evidence for a two type classification. Vision Res. 1977; 17:1049-1055.

3. Levi DM, Harwerth RS, Manny RE. Suprathreshold spatial frequency detection and binocular interaction in strabismic and anisometropic amblyopia. Invest Ophthalmol Vis Sci. 1979;18:714-725.

4. Levi DM, Harwerth RS, Smith EL. Binocular interactions in normal and anomalous binocular vision. Doc Ophthalmol. 1980;49:303-324.

5. Vaegan, Taylor D. Critical period for deprivation amblyopia in children. Trans Ophthalmol Soc UK. 1979;99:432- 439.

6. Hubel DH, Wiesel TN. Binocular interaction in striate cortex of kittens reared with artificial squint. J Neurophysiol. 1965;28:1041-1059.

7. Harrad R, Sengpiel F, Blakemore C. Physiology of suppression in strabismic amblyopia. Br J Ophthalmol. 1996;80:373-377.

8. von Noorden GK, Crawford ML. The lateral geniculate nucleus in human strabismic amblyopia. Invest Ophthalmol Vis Sci. 1992;33: 2729-2732.

9. Chino YM, Cheng H, Smith EL 3rd, Garraghty PE, Roe AW, Sur M. Early discordant binocular vision disrupts signal transfer in the lateral geniculate nucleus. Proc Natl Acad Sci USA. 1994;91:6938-6942.

10. Vedamurthy I, Suttle CM, Alexander J, Asper LJ. Interocular interactions during acuity measurement in children and adults, and in adults with amblyopia. Vision Res. 2007;47:179-188.

11. McKee SP, Levi DM, Movshon JA. The pattern of visual deficits in amblyopia. J Vis. 2003;3:380 - 405.

12. Levi DM, Klein S. Differences in vernier discrimination for grating between strabismic and anisometropic amblyopes. Invest Ophthalmol Vis Sci. 1982;23:398-407.

13. Lema SA, Blake R. Binocular summation in normal and stereoblind humans. Vision Res. 1977;17:691-695.

14. Pardhan S, Gilchrist J. Binocular contrast summation and inhibition in amblyopia: the influence of the interocular difference on binocular contrast sensitivity. Doc Ophthalmol. 1992;82:239-248.

15. Pardhan S, Whitaker A. Binocular summation in the fovea and peripheral field of anisometropic amblyopes. Curr Eye Res. 2000; 20:35- 44 .

16. Holopigian K, Blake R, Greenwald MJ. Selective losses in binocular vision in anisometropic amblyopes. Vision Res. 1986;26:621-630.

17. Hood AS, Morrison JD. The dependence of binocular contrast sensitivities on binocular single vision in normal and amblyopic human subjects. J Physiol. 2002;540:607-622.

18. Campbell FW, Green DG. Monocular versus binocular visual acuity. Nature. 1965;208:191-192.

19. Baker DH, Meese TS, Summers RJ. Psychophysical evidence for two routes to suppression before binocular summation of signals in human vision. Neuroscience. 2007;146:435-448.

20. Georgeson MA, Meese TS. Binocular summation at contrast threshold: a new look. Perception. 2005;34(suppl):141.

21. Meese TS, Georgeson MA, Baker DH. Binocular contrast vision at and above threshold. J Vis. 2006;6:1224-1243.

22. Blake R, Fox R. The psychophysical inquiry into binocular summation. Percept Psychophys. 1973;14:161-185.

23. Baker DH, Meese TS, Georgeson MA. Binocular interaction: contrast matching and contrast discrimination are predicted by the same model. Spat Vision. 2007;20:397-413.

24. Schroder JH, Fries P, Roelfsema PR, Singer W, Engel AK. Ocular dominance in extrastriate cortex of strabismic amblyopic cats. Vision Res. 2002;42:29-39.

25. Chino YM, Smith EL 3rd, Yoshida K, Cheng H, Hamamoto J. Binocular interactions in striate cortical neurons of cats reared with discordant visual inputs. J Neurosci. 1994;14:5050-5067.

26. Gilchrist J, Pardhan S. Binocular contrast detection with unequal monocular illuminance. Ophthalmic Physiol Opt. 1987;7:373-377.
27. Pardhan S. A comparison of binocular summation in young and older patients. Curr Eye Res. 1996;15:315-319.

28. Gagnon RW, Kline DW. Senescent effects on binocular summation for contrast sensitivity and spatial interval acuity. Curr Eye Res. 2003;27:315-321.

29. Valberg A, Fosse P. Binocular contrast inhibition in subjects with age-related macular degeneration. J Opt Soc Am A Opt Image Sci Vis. 2002;19:223-228.

30. Azen SP, Varma R, Preston-Martin S, Ying-Lai M, Globe D, Hahn S. Binocular visual acuity summation and inhibition in an ocular epidemiological study: the Los Angeles Latino Eye Study. Invest Ophthalmol Vis Sci. 2002;43:1742-1748.

31. Pardhan S, Gilchrist J. The importance of measuring binocular contrast sensitivity in unilateral cataract. Eye. 1991;5:31-35.

32. Sireteanu R, Fronius M, Singer W. Binocular interaction in the peripheral visual field of humans with strabismic and anisometropic amblyopia. Vision Res. 1981;21:1065-1074.

33. Gilchrist J, McIver C. Fechner's paradox in binocular contrast sensitivity. Vision Res. 1985;25:609-613.

34. Wetherill GB, Levitt H. Sequential estimation of points on a psychometric function. Br J Math Stat Psychol. 1965;18:1-10.

35. Cornsweet TN. The staircase-method in psychophysics. Am J Psychol. 1962;75:485- 491.

36. Finney DJ. Probit Analysis: Cambridge University Press; 1971

37. Summers RJ, Meese TS. Estimating the 2AFC psychometric function: effects of lapsing, psychophysical procedure and method of curve fitting. Perception. 2007;36:310.

38. van Nes FL, Koenderink JJ, Nas H, Bouman MA. Spatiotemporal modulation transfer in the human eye. J Opt Soc Am. 1967;57: 1082-1088.

39. Foley JM, Legge GE. Contrast detection and near-threshold discrimination in human vision. Vision Res. 1981;21:1041-1053.

40. Tyler CW, Chen CC. Signal detection theory in the 2AFC paradigm: attention, channel uncertainty and probability summation. Vision Res. 2000;40:3121-3144.

41. Smith EL 3rd, Harwerth RS, Crawford ML. Spatial contrast sensitivity deficits in monkeys produced by optically induced anisometropia. Invest Ophthalmol Vis Sci. 1985;26:330-342.

42. Simmons DR. The minimum contrast requirements for stereopsis. Perception. 1998;27:1333-1343.

43. Smallman HS, MacLeod DI. Size-disparity correlation in stereopsis at contrast threshold. J Opt Soc Am A Opt Image Sci Vis. 1994; $11: 2169-2183$

44. Hess RF. Is amblyopia an impediment to binocular function? Eye. 1996;10:245-249.

45. Halpern DL, Blake RR. How contrast affects stereoacuity. Perception. 1988; 17:483-495.

46. Legge GE, Gu YC. Stereopsis and contrast. Vision Res. 1989;29: 989-1004.

47. Hess RF, Liu CH, Wang YZ. Differential binocular input and local stereopsis. Vision Res. 2003;43:2303-2313.

48. Parker AJ, Cumming BG. Cortical mechanisms of binocular stereoscopic vision. Prog Brain Res. 2001;134:205-216.

49. Schor CM. Visual stimuli for strabismic suppression. Perception. 1977;6:583-593.

50. Sireteanu R, Singer W. The "vertical effect" in human squint amblyopia. Exp Brain Res. 1980;40:354-357.

51. Howard IP. Seeing In Depth. Toronto: I Porteous; 2002.

52. Legge GE. Binocular contrast summation I. Detection and discrimination. Vision Res. 1984;24:373-383.

53. Simmons DR. The binocular combination of chromatic contrast. Perception. 2005;34:1035-1042.

54. Schor CM, Maxwell JS, Stevenson SB. Isovergence surfaces: the conjugacy of vertical eye movements in tertiary positions of gaze. Ophthalmic Physiol Opt. 1994;14:279-286.

55. Schor C, Heckmann T. Interocular differences in contrast and spatial frequency: effects on stereopsis and fusion. Vision Res. 1989;29:837-847.

56. Cormack LK, Stevenson SB, Landers DD. Interactions of spatial frequency and unequal monocular contrasts in stereopsis. Perception. 1997;26:1121-1136. 
57. Stevenson SB, Cormack LK. A contrast paradox in stereopsis, motion detection, and vernier acuity. Vision Res. 2000;40:2881-2884.

58. Crewther SG, Crewther DP. Amblyopia and suppression in binocular cortical neurones of strabismic cat. Neuroreport. 1993; $4: 1083-1086$.

59. Ding J, Sperling G. A gain-control theory of binocular combination. Proc Natl Acad Sci USA. 2006;103:1141-1146.

60. Meese TS, Hess RF. Interocular suppression is gated by interocular feature matching. Vision Res. 2005;45:9-15.

61. Smith EL 3rd, Chino YM, Ni J, Cheng H, Crawford ML, Harwerth RS. Residual binocular interactions in the striate cortex of monkeys reared with abnormal binocular vision. J Neuropbysiol. 1997;78: 1353-1362
62. de Belsunce S, Sireteanu R. The time course of interocular suppression in normal and amblyopic subjects. Invest Ophthalmol Vis Sci. 1991;32:2645-2652.

63. Leonards U, Sireteanu R. Interocular suppression in normal and amblyopic subjects: the effect of unilateral attenuation with neutral density filters. Percept Psychopbys. 1993;54:65-74.

64. Rutstein RP. Contemporary issues in amblyopia treatment. Optometry. 2005;76:570 -578.

65. Westendorf DH, Langston A, Chambers D, Allegretti C. Binocular detection by normal and stereoblind observers. Percept Psychophys. 1978;24:209-214.

66. Sengpiel F, Blakemore C. The neural basis of suppression and amblyopia in strabismus. Eye. 1996;10:250-258. 